\title{
The effects of zinc and magnesium ingestion on essential trace- element accumulation in the organs of white rats upon cadmium exposure
}

\author{
Svetlana Nikolaevna Timofeeva*, Ilnur Ravilevich Kadikov, Andrey Aleksandrovich Korchemkin, \\ and Iskander Foatovich Vafin \\ Federal Center for Toxicological, Radiation and Biological Safety, 420075 Kazan, Republic of Tatarstan, Russia
}

\begin{abstract}
Due to high athropogenic loads on the environment, issues surrounding public health and safety in consumable products are being raised with ever-increasing frequency. One toxic metal, whose consumption results in irreparable harm to the health of animals and human is cadmium. To antagonize such toxic effects to human health, magnesium and zinc are considered being essential elements and their combination effects warrant further studies. To this end, we developed a Wistar rat model to look at the combinatorial effects of cadmium with magnesium and zinc consumption on the accumulation of iron and zinc ions in kidney and liver tissues. Our findings suggested that exposure to cadmium ions reduced zinc ion levels in the liver and kidneys, reduced iron ions in the liver (but were increased in the kidneys), decreased magnesium ions in the kidneys but increased their levels within the liver. Moreover, while the consumption of magnesium and zinc ions individually, partially reduced the effects caused by cadmium consumption alone, the simultaneous consumption of zinc and magnesium ions proved to be significantly more effective.
\end{abstract}

\section{Introduction}

Numerous industrial, agricultural, medical, and technological applications of heavy metals can lead to the widespread exposure of humans to potentially toxic environments [1, 2]. Consequently, public health issues revolving around food and health safety have gained considerable attention.

Due to its high level of toxicity to humans and its ubiquitous use in many consumer electronics, cadmium is one metal that has gained central importance in the context of public health [3].

The main sources of this element are air, soil, contaminated water and food - namely rice, cereals, vegetables, seafood and meat (including offal), all of which permit its entry into the human food chain [4]. Once it enters the body of animals and humans, cadmium accumulates in the liver and kidneys and can become the main cause of diseases of these organs.

In the liver, cadmium ions can cause liver failure associated with hepatocyte degeneration, focal necrosis and fat deposition. It can also accumulate within epithelial cells from the proximal tubules of the kidneys, where it can lead to generalized dysfunction of reabsorption and which is characterized by polyuria and low-molecular proteinuria [5-8]. In addition, cadmium ions can functionally impair cell-based protective antioxidant mechanisms and the human reproductive system [9].

In addressing these effects, significant evidence is accumulating to suggest that essential elements (such as magnesium and zinc) can counteract the effects of cadmium by exhibiting protective properties at the cellular level, thus helping to prevent or reduce its adverse effects on health. Conversely, their deficiency can also increase the accumulation of cadmium within internal organs, thereby increasing its toxic effects [1012].

Consequently, the aim of our research was to study the effectiveness of zinc in combination with magnesium on ionic changes associated with the exposure of animals to cadmium.

\section{Materials and methods}

Experiments were conducted in the Laboratory of Technogenic Ecotoxicants at the Federal Center for Toxicological, Radiation and Biological Safety (Russian Federation) over a period of 30 days.

Experimentally, 40 male rats (weighing 250-300 g) were randomly divided into five groups of 8 rats each: Group 1 was a biological negative control; Group 2 received cadmium chloride orally with feed at the rate of $0.6 \mathrm{mg}$ per $\mathrm{kg}$ of feed; and Groups 3, 4 and 5 were fed cadmium chloride (at the same dose as Group 2), with the addition of magnesium/nitric acid (at a dose of 0.8 $\mathrm{mg}$ per head), zinc chloride (at a dose of $5 \mathrm{mg}$ per head) and combined zinc chloride with magnesium/nitric acid) at the doses used for Groups 3 and 4, respectively.

* Corresponding author: svetlana150895@yandex.ru 
Throughout the experiment, the animals were kept under standard sterile conditions with free access to drinking water and balanced granulated feed.

The amount of cadmium, zinc, magnesium and iron was tracked by atomic absorption methodology to study the elementary composition of the liver and kidneys, on an AAC Perkin Elmer Analyst 200 before the experiment and on the 10th, 20th and 30th days of the study. After the $30^{\text {th }}$ day, the animals were subjected to hepatectomy and nephroectomy.

All euthanasia and surgical interventions were performed in accordance with the requirements outlined by the European Convention for the Protection of Vertebrate Animals used for Experimental and Other Scientific Purposes.

\section{Results}

As seen in Fig.1, liver cadmium levels were seen to proportionally increase in Group 2 over the 30 days course from day $10(0.16 \mathrm{mg} / \mathrm{kg})$ to day $30(0.31 \mathrm{mg} / \mathrm{kg}$, above control levels. At the same time, during the experiment, the addition of magnesium to the dietary supplements (Group 3) resulted in the accumulation of liver cadmium at a reduced rate and seen at $0.16 \mathrm{mg} / \mathrm{kg}$ (at day 10) rising to $0.24 \mathrm{mg} / \mathrm{kg}$ (at day 30).

Similarly, in Group 4 (cadmium and zinc), a relatively slower rate of cadmium accumulation was observed which rose from $0.08 \mathrm{mg} / \mathrm{kg}$ (Day 10) to 0.16 $\mathrm{mg} / \mathrm{kg}$ on Day 30.

However, in Group 5 the rate of cadmium accumulation in the liver was observed to increase from 0.09 (Day 10) to $0.17 \mathrm{mg} / \mathrm{kg}$ at day 30. Collectively, such observations suggest that while magnesium significantly reduced the accumulation of cadmium in liver tissue, zinc or magnesium (with zinc) were almost twice as potent at reducing this effect.

Similar trends were also observed for the accumulation of cadmium in rat kidneys. As seen in Fig. 2, magnesium alone (Group 3) reduced cadmium accumulation by $0.17 \mathrm{mg} / \mathrm{kg}$ (Day 10) to around $0.06 \mathrm{mg} / \mathrm{kg}$ (Day 30). As seen with liver tissues, zinc alone (Group 4) or magnesium and zinc consumption (Group 5) reduced the accumulation of cadmium to a significantly lower rate, with Group 5 showing the lowest rates of accumulated cadmium in the kidney at $0.11 \mathrm{mg} / \mathrm{kg}$ over Group 2 levels by day 30 .

The data presented in Fig.3 and 4 show that zinc concentration was significantly decreased in the liver and kidneys of rats after cadmium intoxication by $4.78 \mathrm{mg} / \mathrm{kg}$ (Day 10) to around $11.08 \mathrm{mg} / \mathrm{kg}$ (Day 30) in the liver and by $4.83 \mathrm{mg} / \mathrm{kg}$ (Day 10) to around $8.06 \mathrm{mg} / \mathrm{kg}$ (Day 30) in kidneys. Magnesium or/with zinc supplementation partially corrected this changes and by day 30 the difference was $5.40 \mathrm{mg} / \mathrm{kg}, 1.36 \mathrm{mg} / \mathrm{kg}$, $1.25 \mathrm{mg} / \mathrm{kg}$ in the liver; $3.07 \mathrm{mg} / \mathrm{kg}, 1.48 \mathrm{mg} / \mathrm{kg}$ and $0.32 \mathrm{mg} / \mathrm{kg}$ in kidneys, respectively.

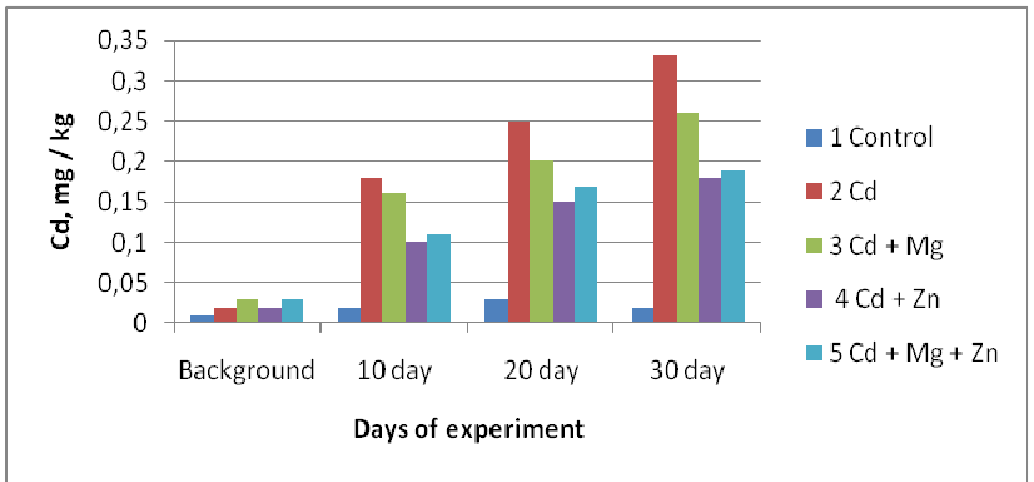

Fig. 1. Accumulation of cadmium in the liver

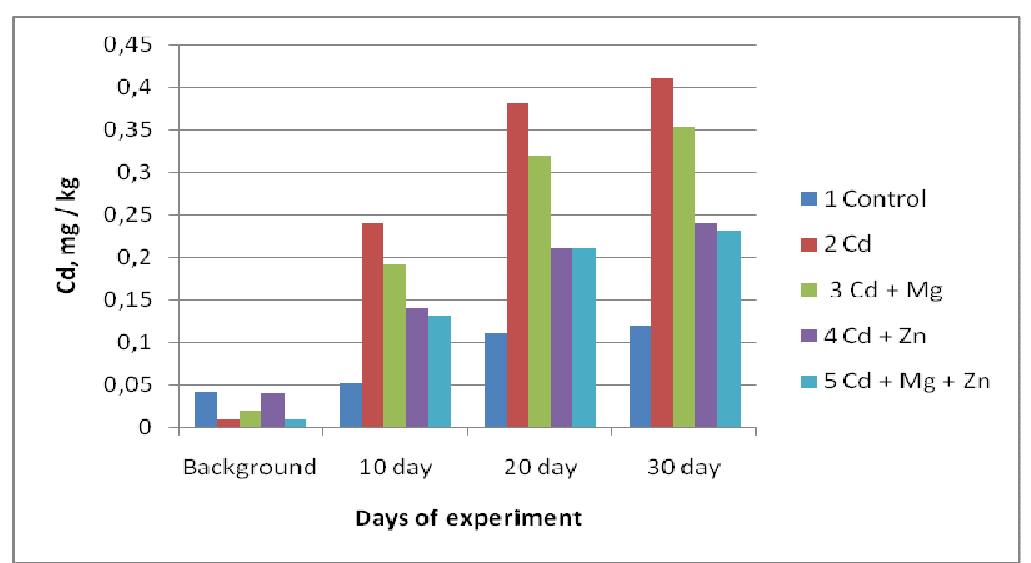

Fig. 2. Accumulation of cadmium in the kidneys 


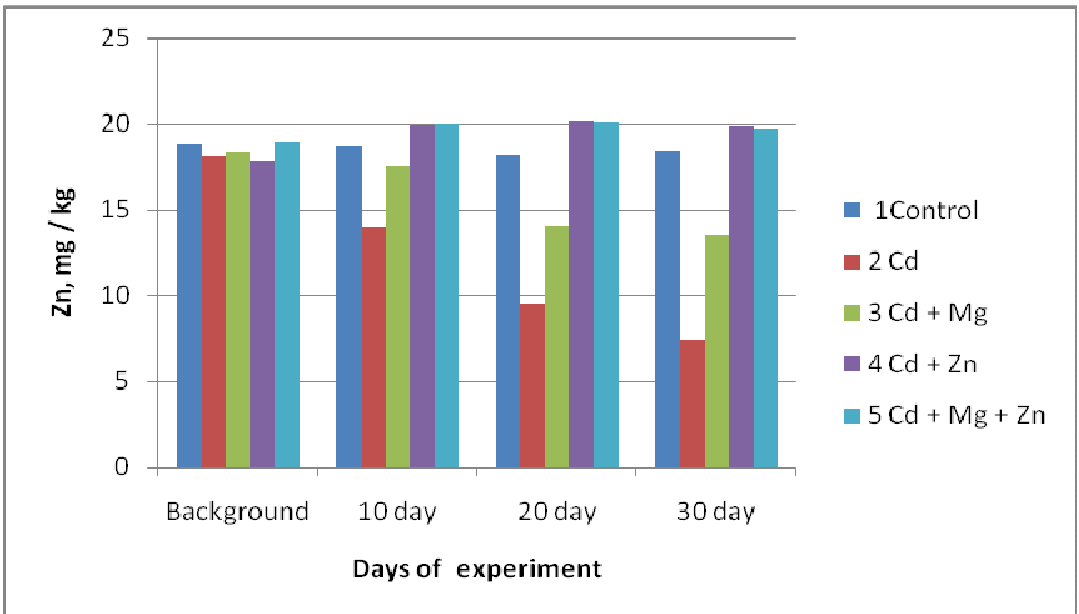

Fig. 3. Accumulation of zinc in the liver

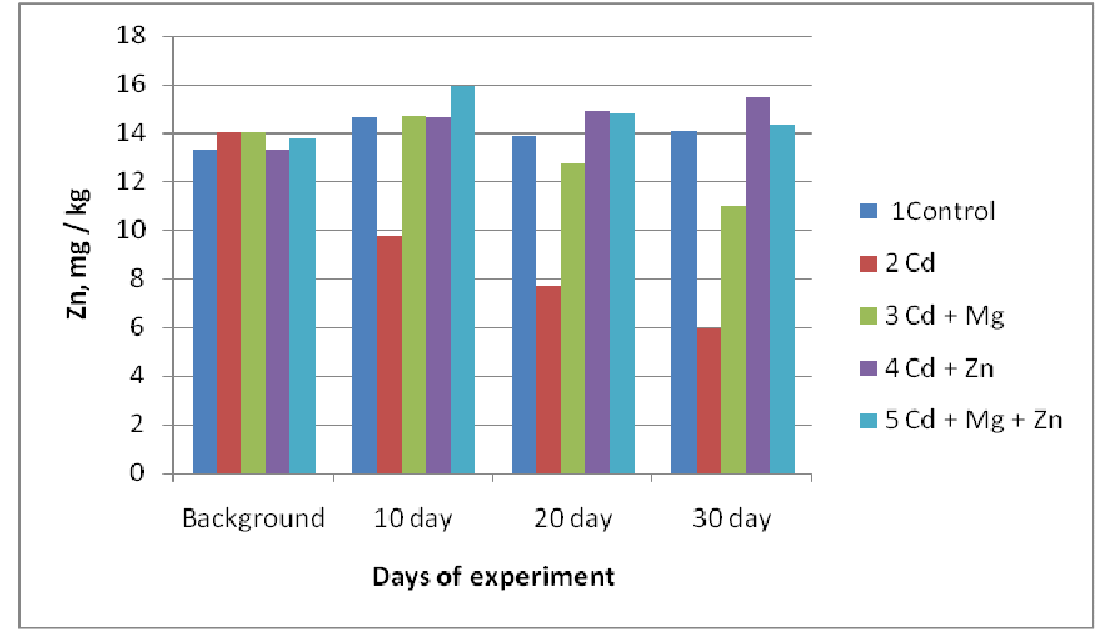

Fig. 4. Accumulation of zinc in the kidneys

As seen in Fig. 5 the level of manganese in the liver was significantly higher in the group of rats exposed to cadmium (Group 2), on day 30 it was $2.45 \mathrm{mg} / \mathrm{kg}$, which is almost 2 times higher than the control parameters. At the same time, the accumulation of manganese gradually decreased in the kidneys (Fig. 6) and by the end of the experiment, its level was halved from the beginning of the experiment $-0.47 \mathrm{mg} / \mathrm{kg}$.

Supplementation of magnesium, zinc, or a combination of them to feed animals that were exposed to cadmium throughout the experience reduced the accumulation of manganese in the liver, and increased it in the kidneys. By the end of the experiment, the rate was $0.68 \mathrm{mg} / \mathrm{kg}$ (Group 3), $1.27 \mathrm{mg} / \mathrm{kg}$ (Group 4) and $1.31 \mathrm{mg} / \mathrm{kg}$ in the liver, $0.72 \mathrm{mg} / \mathrm{kg}$ (Group 3), 0.92 $\mathrm{mg} / \mathrm{kg}$ (Group 4) and $0.98 \mathrm{mg} / \mathrm{kg}$ in the kidneys.

The effects of cadmium on iron accumulation in the liver and kidneys were also analyzed for Groups $1-5$. It can be noted that the accumulation of iron in the liver (Fig. 7) in rats exposed to cadmium first increased and reached the level of $123.72 \mathrm{mg} / \mathrm{kg}$ by 20 days, and by 30 days it decreased to $16.34 \mathrm{mg} / \mathrm{kg}$, which is almost 5 times less than in the control group. Kidney iron levels (Fig. 8) were seen to proportionally increase and by the end of the experience was higher than the control parameters by more than 2 times.

At the same time, the addition of magnesium also increased the accumulation of iron in the liver to 100.30 $\mathrm{mg} / \mathrm{kg}$ (20 Day) and then decreased by the end of the experiment to $51.96 \mathrm{mg} / \mathrm{kg}$, and in the kidneys increased its level to $60.63 \mathrm{mg} / \mathrm{kg}$, but to a lesser extent than in group 2. Iron Levels in groups 4 and 5 were close to control parameters, which mean that the addition of zinc and zinc with magnesium is most effective against the effects of cadmium. 


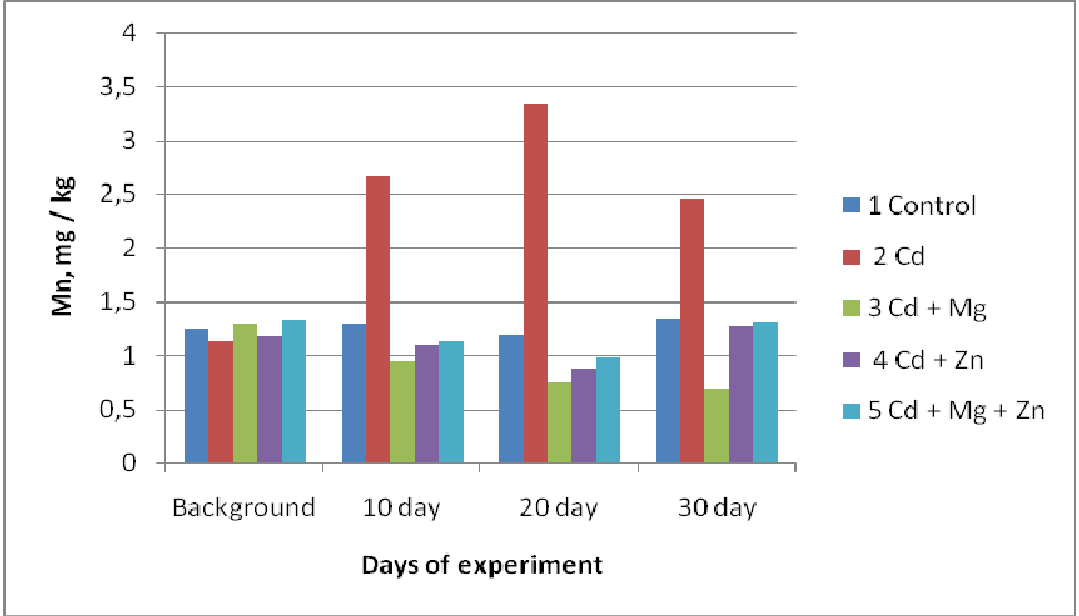

Fig. 5. Accumulation of manganese in the liver

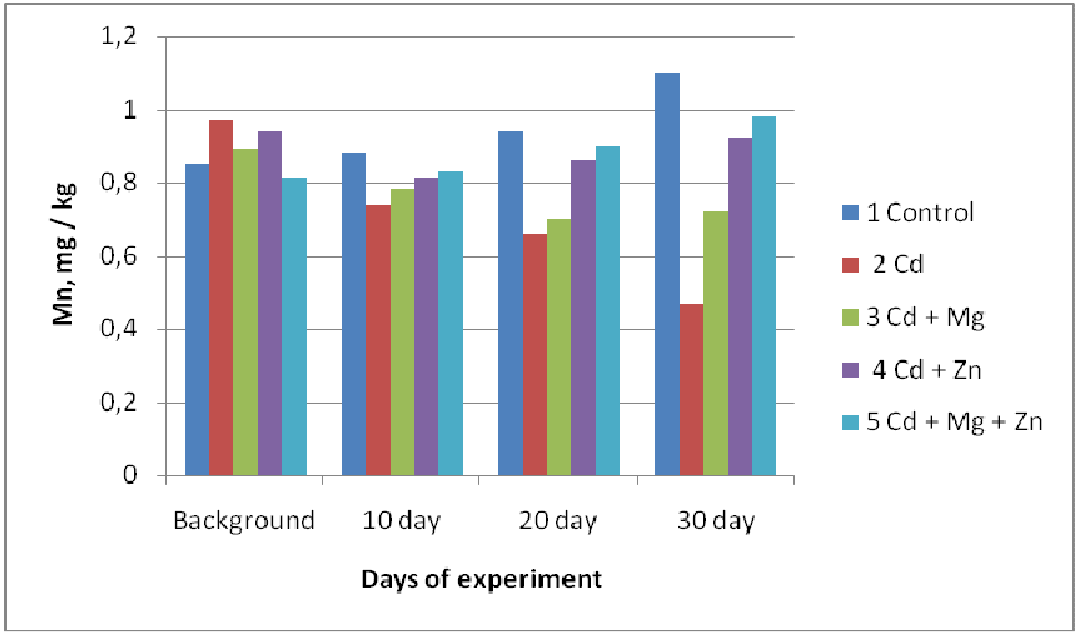

Fig. 6. Accumulation of manganese in the kidneys

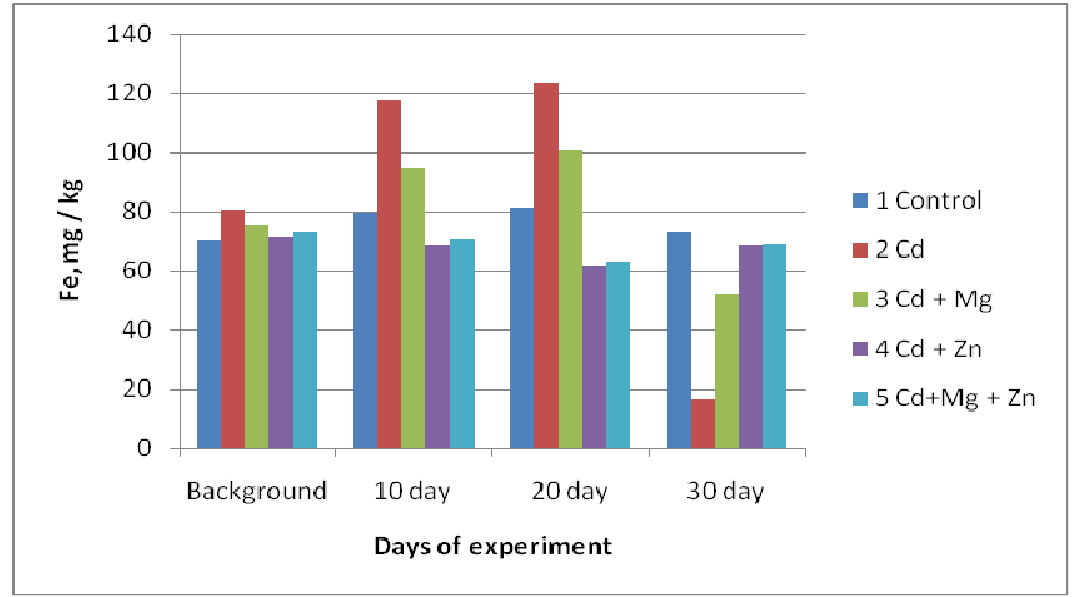

Fig. 7. Accumulation of iron in the liver

\section{Discussion}

It is well documented that cadmium has the detrimental property of accumulating in the liver and kidneys [5, 6]. Additionally, it has also been suggested that as a result of the toxic effect of this metal, the quantitative content of some vital elements in the body, such as zinc, manganese and iron, are also prone to fluctuate.
From our findings and presented herein, we confirm the ability of cadmium ions to accumulate in the liver and kidneys. Additionally, we also found that the amount of zinc, manganese and iron in these tissues vary significantly as a consequence of this. Collectively, at the physiological level such changes can contribute to a number of disorders in the body. For example, a decrease in the level of zinc can lead to deregulation of biologically-protective antioxidant pathways in addition to mechanisms protective for anti-tumor activity $[9,13]$.

\footnotetext{
* Corresponding author: svetlana150895@yandex.ru
} 


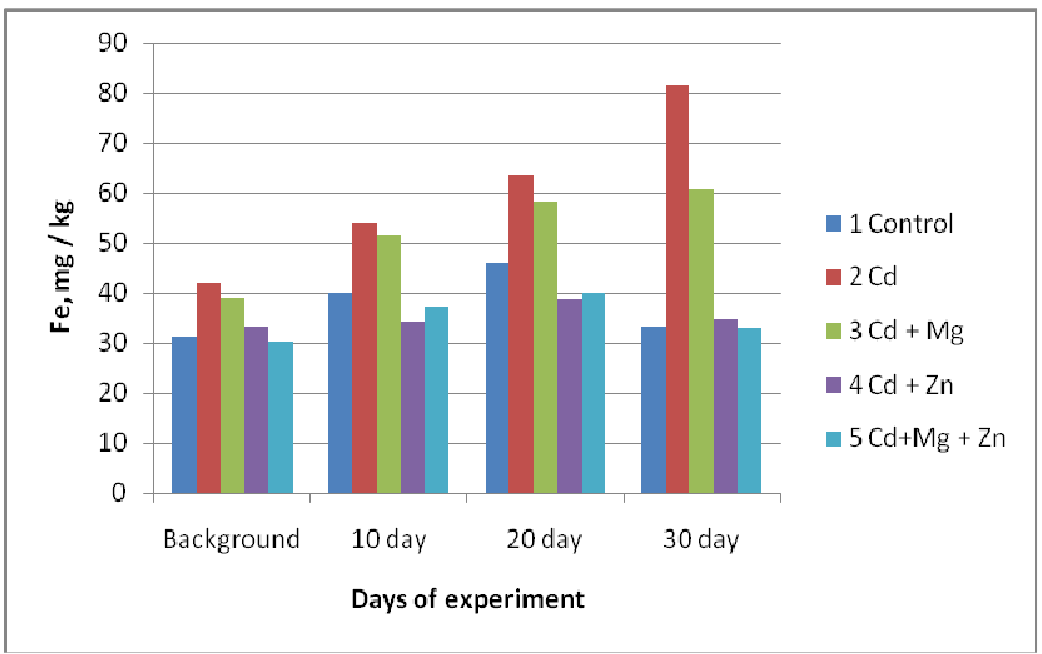

Fig. 8. Accumulation of iron in the kidneys

Mechanistically, there is evidence to suggest that iron and manganese may compete for the same circulatory transport proteins. For example, reduced iron levels can lead to an observed increase in tissue-specific accumulation of manganese [10].

Our results support such a hypothesis particularly upon the ingestion of cadmium. Concurrently, low iron intake can cause iron-deficiency and the onset of anemia, while increased levels of manganese can cause neurotoxic and other pathological conditions [10, 14].

Consequently, the therapeutic use of magnesium and zinc significantly reduces the effects associated with exposure to cadmium and which confirms their potential protective properties against the pathological toxicity of cadmium [11].

\section{Conclusion}

Our studies have shown that ingestion of cadmium quantitatively reduces the levels of zinc in the liver and kidneys. It also decreases iron in the liver (but causes its accumulation in the kidneys) and reduces manganese in the kidney while increaing its levels in the liver. The ingestion of magnesium or zinc individually counteracts the effects of cadmium accumulation in the liver or kidneys while ingestion of magnesium and zinc together proved to be the most effective.

\section{References}

1. V.A. Konychova, I.R. Kadikov, K.H. Papunidi, Evaluation of the contamination level of feed and water in Ryazan regions of the Russian Federation, Veterinary physician, 3, 7-11 (2018)

2. V.A. Konychova, I.R. Kadikov, A.A. Korchemkin, K.H. Papunidi, R.M. Aslanov, E.L. Matveeva, The results of monitoring of heavy metals in feed and water in some regions of the Russian Federation, Scientific Notes of Kazan State Academy of Veterinary Medicine, 240(4), 109-114 (2019)
3. P.B. Tchounwou, C.G. Yedjou, A.K. Patlolla, D.J. Sutton, Heavy Metals Toxicity and the Environment, EXS, 101, 133-164 (2012) DOI: 10.1007/978-3-7643-8340-4_6

4. R. Chunhabundit, Cadmium Exposure and Potential Health Risk from Foods in Contaminated Area, Thailand, Toxicol. Res., 32(1), 65-72 (2016) DOI: 10.5487/TR.2016.32.1.065

5. M.F. Elkhadragy, A.E. Abdel Moneim, Protective Effect of Fragaria Ananassa Methanolic Extract on Cadmium Chloride (CdCl2)-Induced Hepatotoxicity in Rats, Toxicol. Mechan. and Methods, 27, 335345 (2017), DOI: 10.1080/15376516.2017.1285973

6. R.B. Jain, Cadmium and kidney function: Concentrations, variabilities, and associations across various stages of glomerular function, Environ. Pollut., 256, 113361 (2019) DOI: org/10.1016/j.envpol.2019.113361

7. V.S. Arroyo, K.M. Flores, L.B. Ortiz, L.E. GómezQuiroz, M.C. Gutiérrez-Ruiz, Liver and Cadmium Toxicity, J. of Drug Metabol. \& Toxicol., S5, 001 (2012) DOI: 10.4172/2157-7609.S5-001

8. W.C. Prozialeck, J.R. Edwards, Mechanisms of Cadmium-Induced Proximal Tubule Injury: New Insights with Implications for Biomonitoring and Therapeutic Interventions, J. of Pharmacol. and Experim. Therap., 343(1), 2-12 (2012) DOI: 10.1124/jpet.110.166769

9. H. Jemaia, I. Messaoudib, A. Chaouchc, A. Kerkeni, Protective effect of zinc supplementation on blood antioxidant defense system in rats exposed to cadmium, J. of Trace Elem. in Med. and Biol., 21, 269-273 (2007) DOI: 10.1016/j.jtemb.2007.08.001

10. K.J. Horning, S.W. Caito, K. Grace Tipps, A.B. Bowman, M. Aschner, Manganese Is Essential for Neuronal Health, Annu. Rev. Nutr., 35, 71-108 (2015) DOI: 10.1146/annurev-nutr-071714-034419.

11. N. Babaknejad, S. Bahrami, A. Asghar Moshtaghie, H. Nayeri, P. Rajabi, F. Golshan Iranpour, Cadmium Testicular Toxicity in Male Wistar Rats: Protective 
Roles of Zinc and Magnesium, Biol. Trace Elem.t Res., 185, 106-115 (2018) DOI: org/10.1007/s12011-017-1218-5

12. Z. Bulat, D. Dukic- Cosi, B. Antonijevic et al., Effect of Magnesium Supplementation on the Distribution Patterns of Zinc, Copper, and Magnesium in Rabbits Exposed to Prolonged Cadmium Intoxication, Sci. World J., 572514 (2012) DOI: $10.1100 / 2012 / 572514$
13. D. Skrajnowska, B. Bobrowska-Korczak, Role of Zinc in Immune System and Anti-Cancer Defense Mechanisms, Nutrients, 11(10), 2273 (2019) DOI: 10.3390/nu11102273

14. J. Baird-Gunning, J. Bromley, Correcting iron deficiency, Austral. Prescribe, 39(6), 193-199 (2016) DOI: 10.18773/austprescr.2016.069 